These included Prof Ann Soenarta (Indonesia, Prof Talma Rosenthal (Israel), Prof Suzanne Oparil (USA), Prof Bonita Falkner (USA) and Prof Lisheng Liu (China).

Over the course of the next 2 years, many of these ambitions were beginning to be realised. By 2018, at the biennial meeting held in Beijing, ISH had secured a second woman president (Alta Schutte, 2018-2020), the number of women in ISH leadership committees had grown and there was a marked increase (from $20 \%$ to $50 \%$ ) in women representation at the Beijing meeting as shown in the graphs.

Increased representation of women at ISH 2018

Moreover, the WiHR group led 3 special sessions at the 2018 Beijing meeting (Special mentoring session 'Women in Hypertension Research- maximising opportunities and research career goals'; Breakfast workshop "Hypertension and cardiovascular disease in women" and Clinical Science Session 'Hypertension in pregnancy/hypertension in women'.

\title{
The future of the programme
}

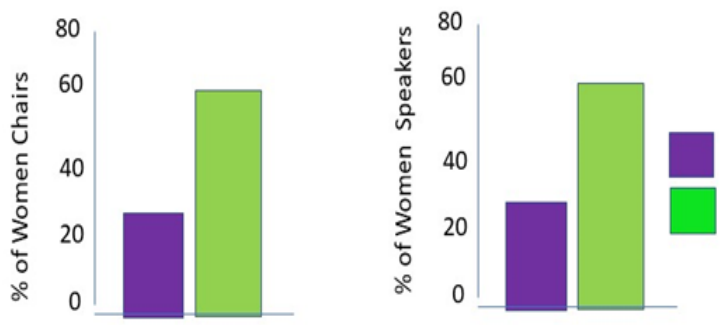

2016 2018

As I look back over the past few years from when the idea of the WiHR programme was conceived, to its creation and now to see it as a well-established initiative under the umbrella of ISH, it is with tremendous pride and honour that I hand over the leadership to Ulrike (Muscha) Steckelings as the next Chair of the committee. I am truly grateful to Neil Poulter (President 2016-2018) and the ISH Executive, for having being so supportive in the initial idea. It has also been a great privilege working with so many dedicated enthusiastic and hard-working committee members, colleagues and friends, committed to the WiHR mission. There is no doubt in my mind that under the outstanding leadership of Muscha and her committee, the goal to 'promote women scientists and clinicians so that they can fulfil their career aspirations in hypertension and related cardiovascular diseases' will be respected and that the programme and network will continue to grow and strengthen.

Rhian M Touyz - Rhian.Touyz@glasgow.ac.uk

NEWS, OLD NEWS, FAKE NEWS

DOI: $10.30824 / 1906-11$

\section{"Are you lonesome tonight?" Stephan Rössner}

\section{Elvis Presley 1935-1977}

Elvis Aaron Presley was a cultural icon, widely known simply as Elvis, the king of rock-and-roll. His early musical style was a fusion of country, rhythm and blues and always with a strong backbeat. Elvis has been regarded as one of the most important figures of the popular culture of last century and has sold about one billion records worldwide. He never had any formal musical training and could not read music but played by ear. From the mid fifties onwards Elvis had a spectacular career with admirers all over the world.

Elvis made numerous films, some of which were flops, while others topped the lists. His military service in Germany was followed by thousands of fans but this was also the period in time when Elvis was first introduced to the drugs that would result in ill health and eventually to his premature death. Having been a slender and well-trained young man with a particular interest in karate, Elvis continuously put on weight and ended his life grossly obese.

Elvis's dietary habits were studied and analysed and even described in a television documentary. There was even a cookery book describing what Elvis appreciated eating. It was said that Elvis had a favourite super-sandwich which was flown in especially for him from Denver to Graceland, Tennessee. The recipe is not very appetising: a large baguette, half a kilogram of bacon, a big can of peanut butter plus a jar of grape jelly. Bread is toasted in the oven, the soft dough is removed and filled with fried bacon, peanut butter and jelly. It was said that a "sandwich" of this size would feed ten people - but Elvis had it all by himself. Elvis had extremely simple eating habits and his wife Priscilla, whom he met when she was only 14 years old and married seven years later, described Elvis's dietary habits in her memoirs Elvis and Me. To cook for Elvis was simple, "you just took what there was at home and burnt it". 
The king had special demands for what he wanted available around the clock and in his home there was one special chef available just to supply him with what he desired for the moment. There was always minced meat, Pepsi-Cola, orange juice, hamburger bread, potatoes, onions and fresh fruit plus huge amounts of milk, sauerkraut and Vienna sausages, banana pudding, ice cream, cookies and chewing gum.

His favourite night-time snack was a simple sandwich: two slices of white bread covered with mashed banana, peanut butter and fried in a lot of margarine. The recipe suggests that it should be eaten with knife and fork...

Elvis hated strange food. When he once was served snails he refused to eat, arguing that "I don't want to eat anything I can step on when I walk out of my front door". In that respect his aversion is obviously shared by many others.

Pictures showing Elvis together with President Richard Nixon at the White House reveal a 35-year-old man who is already overweight. Elvis wanted Nixon to take action against drugs and saw the Beatles as an example of antiAmericanism and drug abuse in the popular culture. This was obviously ironic since Elvis himself at that time was a manifest abuser.

The outfits in which Elvis is seen on stage became wider and wider to cover his ever-growing body. Elvis became fatter and fatter, was inaudible when he was singing on stage, fell out of cars, hung on to the microphone like a lamppost and shortened his performances but would still draw large audiences. In 1977 he would sit in his rooms almost unable to move and he was suffering from glaucoma, high blood pressure, liver damage, gastrointestinal problems and degenerative arthritis, all potentially related to his weight problem and drug abuse.

Elvis was found dead in his bathroom when his staff came to pick him up to fly out of Memphis for another concert tour. Hundreds of thousands of fans followed the casket. He was buried in Memphis next to his mother but an attempt was made to steal his body 11 days after the funeral and so the remains of both Elvis and his mother were reburied safe inside the Graceland Meditation Garden.

There are several food references in his lyrics: Money honey, blueberry hill, crawfish and others.

\section{May Measurement Month 2019: The global Blood Pressuring Screening Campaign builds momentum across the world}

Thanks to the commitment and generous support of many national hypertension and cardiac societies, thousands of volunteers from over 80 countries came together for the third time to run the largest mass synchronised blood pressure screening campaign during May Measurement Month (MMM) 2019.

Once again we have seen a busy MMM across our social media feeds (@maymeasure) with photos of blood pressure screening sites in many diverse locations in both urban and rural areas showing some great imagination. These included hospital waiting rooms, universities, workplaces, pop up events in parks, markets and shopping malls, places of worship and door to door campaigns in remote villages. We also saw some new screening ideas, at yoga centres, world heritage sites and football stadiums. In Sri Lanka the MMM team even incorporated MMM into the medical test required for drivers' licences, National Police in the Philippines had their blood pressure measured and the Nepal MMM team used their social media network to promote their campaign so widely that they received a request to hold an MMM screening site at a wedding banquet! 2019 has been a busy year for publication too, with MMM's first supplement of 39 national papers from MMM17 published in the European Heart Journal Supplement in early April. 